\title{
Selective IgA deficiency and spondyloarthropathy: A distinct disease?
}

\author{
Gabriel Herrero-Beaumont, Jacome Bruges Armas, Judith Elswood, Robert K Will, \\ Andrei Calin
}

\begin{abstract}
A woman with selective IgA deficiency and severe ankylosing spondylitis (AS), complicated by intractable peripheral arthritis, is described. Three previous cases of selective IgA deficiency and AS have been reported, all of whom had severe AS. It is suggested that selective IgA deficiency is a poor prognostic factor in AS and therefore warrants further investigation to determine the clinical course of such patients.
\end{abstract}

Selective IgA deficiency is the most common immunoglobulin deficiency. Its prevalence in various populations ranges from $0 \cdot 1 \%$ to $0 \cdot 2 \%$. $^{1}$ IgA deficiency has been associated with several rheumatic diseases, but only three previous cases of selective IgA deficiency and ankylosing spondylitis (AS) have been reported, all of whom had severe AS. ${ }^{2-4}$ We describe selective IgA deficiency in a woman with severe AS and peripheral arthritis.

\section{Case report}

The patient was a 41 year old white woman who had had a normal childhood, but who had had frequent sore throats when aged about 16. She was allergic to tetracycline.

At the age of 17 her left knee swelled, followed shortly afterwards by the right knee. In the following year her neck and back became stiff and painful. She was diagnosed at the age of 18 as having AS. Later she developed pain in the feet, followed by disease of the elbows, metacarpophalangeal (MCP), and proximal interphalangeal (PIP) joints. By the age of 28 she had developed right wrist pain, and at 29 the wrist was considerably deformed and she had a spontaneous rupture of the extensor tendons to the right index, middle, and ring finger. Subsequently, both knees and the left ankle became tender and swollen and she had a stiff right shoulder.

On examination she had subluxation and ulnar deviation of the MCP joints on the left. The elbows had bilateral fixed flexion deformities of $5^{\circ}$ on the left and $10^{\circ}$ on the right, with a bony exostosis. External rotation of the shoulders was reduced bilaterally. There was virtually no movement of the neck and spine. The knees had bilateral synovial swelling and a popliteal cyst.

She had a long history of recurrent anaemia of chronic disease and had been transfused 7 units without apparent transfusion reaction. Laboratory tests indicated a severe inflammatory pattern with a platelet count of $548 \times 10^{9} / 1$ and raised plasma viscosity of $2 \cdot 27 \mathrm{cP}$. Rheumatoid factor was negative, as were antinuclear antibodies and anti-DNA. IgG was $24.6 \mathrm{~g} / \mathrm{l}$ and IgM $1.2 \mathrm{~g} / \mathrm{l}$. Various determinations of $\operatorname{IgA}$ in serum gave a concentration of $<0.1 \mathrm{~g} / \mathrm{l}$. HLA types were $\mathrm{Al}$, 2; B8, 27.

Bone marrow showed no specific changes. Immunofluorescence showed $85 \%$ of plasma cells producing $\gamma$ chains, $15 \% \mu, 69 \% \chi$, and $28 \%$ $\lambda$ chains. No IgA producing plasma cells were seen. Gastric biopsy specimens from the body and antrum showed mild gastritis with light patchy plasma cell infiltrates. There was a complete absence of staining when the tissues were treated with anti-IgA. Other reagents gave a similar reaction to that seen in the control.

She was treated with non-steroidal antiinflammatory drugs; gold was stopped on two occasions owing to proteinuria, and penicillamine was stopped after nine months because of lack of efficacy. Pelvic radiographs showed ankylosis of the sacroiliac joints. The left hip had severe protrusion with marked concentric loss of joint space. The joint surfaces were a little irregular with subchondral sclerosis and cyst formation. The right hip showed modest joint space loss. Radiographs of the peripheral joints showed marked erosive arthritis affecting the knees, elbows, wrists, MCP, and PIP joints.

Her paternal grandmother and maternal aunt had AS. Immunoglobulin studies on the latter showed IgG 8.55 g/l (normal range 8-18), IgA $0.93 \mathrm{~g} / \mathrm{l}$ (normal range $0.9-4.5$ ), and IgM 2.9 g/l (normal range $0 \cdot 6-2 \cdot 8$ ).

\section{Discussion}

We describe a female patient with selective IgA deficiency and severe spondylitic disease, later complicated by intractable peripheral arthritis. Although the unusual coexistence of two diseases (AS and 'seronegative rheumatoid arthritis') cannot be excluded, there is no reason to suppose that this case did not represent a single diagnosis - namely, severe intractable AS with peripheral arthritis. The patient was seronegative, had no subcutaneous nodules or other complications of rheumatoid arthritis, and radiographs showed a tendency to ankylosis. There was no evidence of psoriasis, enterocolitis, or features of Reiter's syndrome.

Serum IgA may have a role in the pathogenesis of AS. ${ }^{5}$ Some authors have suggested that increased concentrations of IgA are consistent with an antibody reaction to a microbial triggering agent acting across an IgA secreting organ such as the gut. This theory has been supported 
by the demonstration of a correlation between the serum concentrations of IgA and periods of activity of AS, and also with the IgA immune complex concentrations. ${ }^{5-7}$ The effect of IgA deficiency on the symptoms and course of AS is not known, however. The severe spondylitis and intractable peripheral arthritis of our patient and the other three patients previously reported $^{2-4}$ may be contrasted with the not particularly aggressive forms of juvenile chronic arthritis and systemic lupus erythematosus usually found with selective IgA deficiency. ${ }^{89}$ Possibly, intestinal IgA protects patients with AS from severe disease. Alternatively, selective IgA deficiency would permit increased antigenic challenge in the upper respiratory tract or in the gut with increased antigen in the blood. ${ }^{10}$ In fact, two of the four patients reported had systemic amyloidosis, ${ }^{24}$ an uncommon complication of AS. ${ }^{11}$

In conclusion, further investigation and accurate reporting of cases of selective IgA deficiency associated with AS are warranted to determine the clinical course of such patients, given that the first four cases had a particularly poor prognosis. If this is substantiated, aggressive treatment might be required, perhaps with immunoglobulin replacement.

Dr Herrero-Beaumont was supported by a grant from Fundacion
Jimenez Diaz. Dr Armas received a grant from the Autonomous Government of Acores.

1 Blease R M, Lane E C. AIDS and other immunodeficiency diseases. In: Kelley $W$ N, Harris E D, Ruddy S, Sledge C B, eds. Textbook of rheumatology. 3rd ed. Philadelphia: Saunders, 1989: 1368-9.

2 Modigliani R, Huet P M, Bognel J L, et al. Enteropathie et carence selective en IgA. A propos de trois nouvelles observations. Ann Med Interne (Paris) 1971; 122: 925-30.

3 Good A E, Cassidy J T, Mutchnick M G, Reed R E, Lederman H M. Ankylosing spondylitis with selective IgA deficiency and a circulating anticoagulant. $\mathcal{J}$ Rheumatol 1977; 4: 297-302.

4 Lovy M, Andersen P, Steigerwald J. Ankylosing spondylitis, selective IgA deficiency and systemic amyloidosis with intrasynovial amyloid deposition. $\mathcal{F}$ Rheumatol 1983; 10: 337-41.

5 Franssen M J A M, van de Putte L B A, Gribnau F W J. IgA serum levels and disease activity in ankylosing spondylitis: a prospective study. Ann Rhewm Dis 1985; 44: 766-71.

6 Mackiewicz A, Khan M A, Reynolds T L, van der Linden S, Kushner I. Serum IoA, Rute phase proteins, and olycosylation of $\alpha_{1}$-acid glycoprotein in ankylosing spondylitis. sylation of $\alpha_{1}$-acid glycoprotein in
Ann Rhewom $D$ is 1989; 48: 99-103.

7 Peeters A J, van den Wall Bake A W L, van Dalsen A D, Westedt $M$ L. Relation of microscopic haematuria in ankylosing spondylitis to circulating IgA containin immune complexes. Ann Rherw Dis 1988; 47: 645-7.
Cassidy J T, Petty R E, Sullivan D B. Occurrence of selective IgA deficiency in children with juvenile rheumatoid arthritis. Arthritis Rhewm 1977; 20: 181-3.

9 Back G L, Pillay V K G, Kark R M. IgA deficiency in systemic lupus erythematosus. Acta Rheumatologica Scandinavica 1971; 17: 63-71.

10 Cunningham C H, Brandei W E, Good R A, Day N K. Bovine antigens and the formation of circulating immune complexes in selective immunoglobulin A deficiency. $\mathcal{J}$ Clin Invest 1979; 64: 272-9.

11 Jayson M I V, Salmon P R, Harrison W. Amyloidosis in ankylosing spondylitis. Rheumatology and Rehabilitation 1971; 11: 78-82. 